\title{
Atmospheric Conditions and Increasing Temperature over the Tibetan Plateau during Early Spring and the Pre-Monsoon Season in 2008
}

\author{
Kenji TANIGUCHI \\ Faculty of Environmental Design, Kanazawa University, Kanazawa, Japan \\ Toru TAMURA \\ Swiss Reinsurance Company Ltd, Tokyo, Japan \\ Toshio KOIKE \\ Department of Civil Engineering, the University of Tokyo, Tokyo, Japan \\ Kenichi UENO \\ Faculty of Life and Environmental Sciences, University of Tsukuba, Tsukuba, Japan \\ and \\ Xiangde XU \\ Chinese Academy of Meteorological Science, Beijing, China \\ (Manuscript received 29 March 2011, in final form 31 October 2011)
}

\begin{abstract}
An intensive field observation was implemented for the Tibetan Plateau from early spring to the mature season of the Asian summer monsoon in 2008. Atmospheric conditions in the early spring and the pre-monsoon season are investigated in detail using radiosonde observation data. In early spring, atmospheric profiles show unstable stratification, which can result in strong dry convection. In the mixing layer developed by convection, the potential temperature $(P T)$ increases significantly during the day near the surface. On the other hand, there is no clear tendency in the variation in $P T$ above the mixing layer. In the pre-monsoon season, there is a clear increasing trend of $P T$ at each level from the surface to the upper troposphere. The largest heating amount and trend are observed in the upper troposphere. Since cumulus activities become less frequent in the pre-monsoon season, the upper tropospheric heating in this season cannot be caused by latent heat release, as noted in past studies. On the other hand, the profiles of $P T$ show quite stable stratification and the mixing layer is shallow in this period. Under such a condition, the remarkable heating in the upper layers cannot be due to the development of the mixing layer. In past studies, a dry convection induced by strong surface heating is thought to be a possible cause of atmospheric heating over the Tibetan Plateau in the pre-monsoon season. However, the observation results reveal
\end{abstract}

Corresponding author: Kenji Taniguchi: Faculty

of Environmental Design, Kanazawa University,

Kakuma-machi, Kanazawa, 920-1192 Japan.

E-mail: taniguti@t.kanazawa-u.ac.jp

(C) 2012, Meteorological Society of Japan 
that such a locally induced convection is not enough for the significant heating. In addition, the temporal variations of $P T$ at the eastern and western part of the plateau show some similarity. This similarity and the characteristics in dry and wet convections denote some synoptic scale processes may have important roles in the heating over the Tibetan Plateau in the pre-monsoon season.

\section{Introduction}

The Tibetan Plateau is an important component of the Asian summer monsoon system. Recently, Boos and Kuang (2010) noted that warm and cold air in the south and north of the plateau are insulated by the orography, which is the main mechanism by which the plateau forms and maintains the monsoon in South Asia. However, atmospheric heating over the plateau also affects the meteorological and climatological conditions of East Asia, especially in southwestern China. Zhao and Chen (2001) presented negative correlation between the summer heat source of the plateau and convective activity over a wide region in Eastern Asia. Hsu and Liu (2003) showed that strong heating over the plateau is associated with heavy rainfall in JJA (June, July, August) in central China, the southern Korean Peninsula, and most of Japan. They presented a similar anomalous tendency in atmospheric heating between JJA and MAM (March, April, May), and for this persistent heating, they suggested that a more accurate estimate of springtime heating would be useful in predicting summertime rainfall in East Asia. Duan and Wu (2005) investigated the relationship between rainfall and atmospheric circulation in July over East Asia and sensible heating from April to June over the plateau, and demonstrated that strong sensible heating over the plateau leads to a positive rainfall anomaly over the plateau and the area southeast of the plateau, but a negative rainfall anomaly to the north, northwest, and west of the plateau. These results disagree with those of Zhao and Chen (2001), who described a rainfall anomaly to the east of the plateau related to heating over the plateau. The relationship between atmospheric heating over the plateau and rainfall in Asia requires further study.

Therefore, the heating process of the atmosphere over the Tibetan Plateau is one of the most important factors in the Asian summer monsoon system. Luo and Yanai (1984) suggested that, using radiosonde and surface observation data, dry thermal convection formed near the heated ground surface in the afternoon has a role in tropospheric heating over the plateau before the rainy season. Yanai and $\mathrm{Li}$ (1994) noted that a large daytime temperature difference between ground and air generates a layer with a super-adiabatic lapse-rate near the surface that leads to dry convection and upward movement of the air mass. They concluded that sensible heat flux due to the upward flow is the major source of heating over the plateau before the rainy season. Ueda et al. (2003) analyzed 4DDA data obtained by the GEWEX Asian Monsoon Experiment for the western Tibetan Plateau from May to August 1998 and demonstrated the importance of condensation heating in terms of the heat balance during the pre-onset phase of the summer monsoon. They emphasized the importance of condensation heating in terms of the first transition of the Asian summer monsoon and showed that the eastern plateau remains a heat sink with clear subsidence during May and June. Taniguchi and Koike (2007) examined radiosonde observation data obtained for the eastern plateau and conducted numerical simulations employing a regional weather prediction model. They showed cumulus convection was indispensable in warming the upper troposphere over the plateau during the season before the summer rains.

To understand the heating over the Tibetan Plateau, synoptic scale conditions have to be also considered. Murakami and Ding (1982) investigated the characteristics of upper-tropospheric circulation over the Eurasian continent during the early summer. They showed a warm region in the southwest of the plateau and a significant convergence area in the west of the plateau. They also presented a dominant adiabatic heating before rainy season and suggested the heating is due to subsidence motion in that region. He et al. (1987) examined the warming over the area from Iraq to the western plateau in the second transition period (or the pre-onset of rainy season) and presented the relationship with the development of the $200 \mathrm{hPa}$ anticyclone over this region. And they concluded that the dominant mechanism for the warming centered over the Iranwestern plateau region is adiabatic warming due to the subsidence motion. Yanai et al. (1992) also concluded that atmospheric heating in the west of the plateau is caused by adiabatic heating associated 
with subsidence motion. Tamura et al. (2010) examined the climatological conditions of the atmosphere in Asia with reanalysis data, and discussed the mechanism of upper tropospheric warming over the plateau. They also suggested that adiabatic subsidence plays an important role and adiabatic warming to the southwest of the plateau is closely related with anomalous Hadley-type circulation induced by the strong tropical convections.

Processes of atmospheric heating over the plateau are understood to a large extent; however, several topics require further investigation (e.g., the effect of the diurnal cycle and local and large-scale interaction). At the same time, intensive observations have been made from the pre-monsoon season to the monsoon season (or the rainy season), but a detailed investigation has not been possible owing to a lack of in-situ observation data in other seasons. In some studies, the heating over the plateau was investigated by temporally mean atmospheric conditions for several dozen days (e.g., Luo and Yanai 1984; He et al. 1987), or vertically mean conditions for several layers. In the seasonal progression of the Asian summer monsoon, especially in pre-monsoon season, atmospheric conditions drastically changes and these variations are different between layers. Then, detail investigations are indispensable to understand accurate processes of the atmospheric heating.

In 2008, a series of intensive observation campaign was implemented at various observation sites in China under the framework of the Japan International Cooperation Agency (JICA) and involving cooperation between Japan and China. The field campaigns were implemented in three intensive observation periods in China, including a wide region of the Tibetan Plateau. The target periods of the campaigns are early spring, the pre-monsoon season, and the mature season of the summer monsoon. In this study, using the intensive observation data, conditions of the atmosphere over the plateau are investigated in detail in the less-observed seasons, and the processes of atmospheric heating are discussed.

In Section 2, observations and datasets are briefly overviewed. In Section 3, seasonal and diurnal variations of the atmosphere over the plateau are investigated using the observation data. In Section 4 , the increase in atmospheric temperature in the upper troposphere is discussed from the view point of synoptic-scale conditions. Finally, a summary and discussions are presented in Section 5.

\section{Observations and data}

\subsection{Overview of observations}

The "Japan-China Meteorological Disaster Cooperated Research Center" project has been run by the JICA since 2005. Its goal is the mitigation of meteorological disasters and efficient management of water resources in East Asia. Observational equipment has been upgraded over the Tibetan Plateau and southeastern China. At the same time, a numerical prediction model has been developed using those observation data.

Three intensive observation periods (IOPs) were scheduled for 2008: 25 February-19 March, 13 May-12 June, and 20 June-19 July. Instruments including a radiosonde observation system were used in the observations during those periods. Intensive radiosonde observations (four times per day) were made at two observation sites on the Tibetan Plateau (Naqu and Gaize). Figure 1 shows the terrain of the plateau and the locations of the two observation sites. Naqu is located on the eastern plateau at $31.29^{\circ} \mathrm{N}, 92.04^{\circ} \mathrm{E}$ and $4508 \mathrm{~m}$ above sea level (mASL) and Gaize on the western plateau at $32.09^{\circ} \mathrm{N}, 84.25^{\circ} \mathrm{E}$ and $4415 \mathrm{mASL}$. In this paper, the radiosonde observation data for $\mathrm{Naqu}$ and Gaize collected during the first IOP (IOP1) and second IOP (IOP2) are used. The radiosonde observations were made at 0100, 0700, 1300 and 1900 Beijing standard time (BST). A Vaisala global positioning system (GPS) radiosonde system and an L-band system were used in Gaize and Naqu, respectively. Detailed data (taken every $2 \mathrm{~s}$ ) are available for Gaize, and data at standard pressure and significant pressure levels are available for Naqu.

Although an intensive observation campaign was implemented in May 1998 under the framework of the GEWEX Asian Monsoon Experiment, the observation data were not as dense as those obtained in the JICA IOPs in 2008. Especially, the vertical profile of the atmosphere was observed in more detail in the IOPs. There was no intensive radiosonde observation in the plateau in early spring before this project. Using the observation data obtained in 2008, atmospheric structures and processes of diurnal and seasonal variations in atmospheric temperature can be investigated more closely than those in past studies.

\subsection{Other datasets}

To investigate synoptic-scale conditions, a reanalysis product published by the Japan Meteorological Agency (JMA) Climate Data Assimilation 

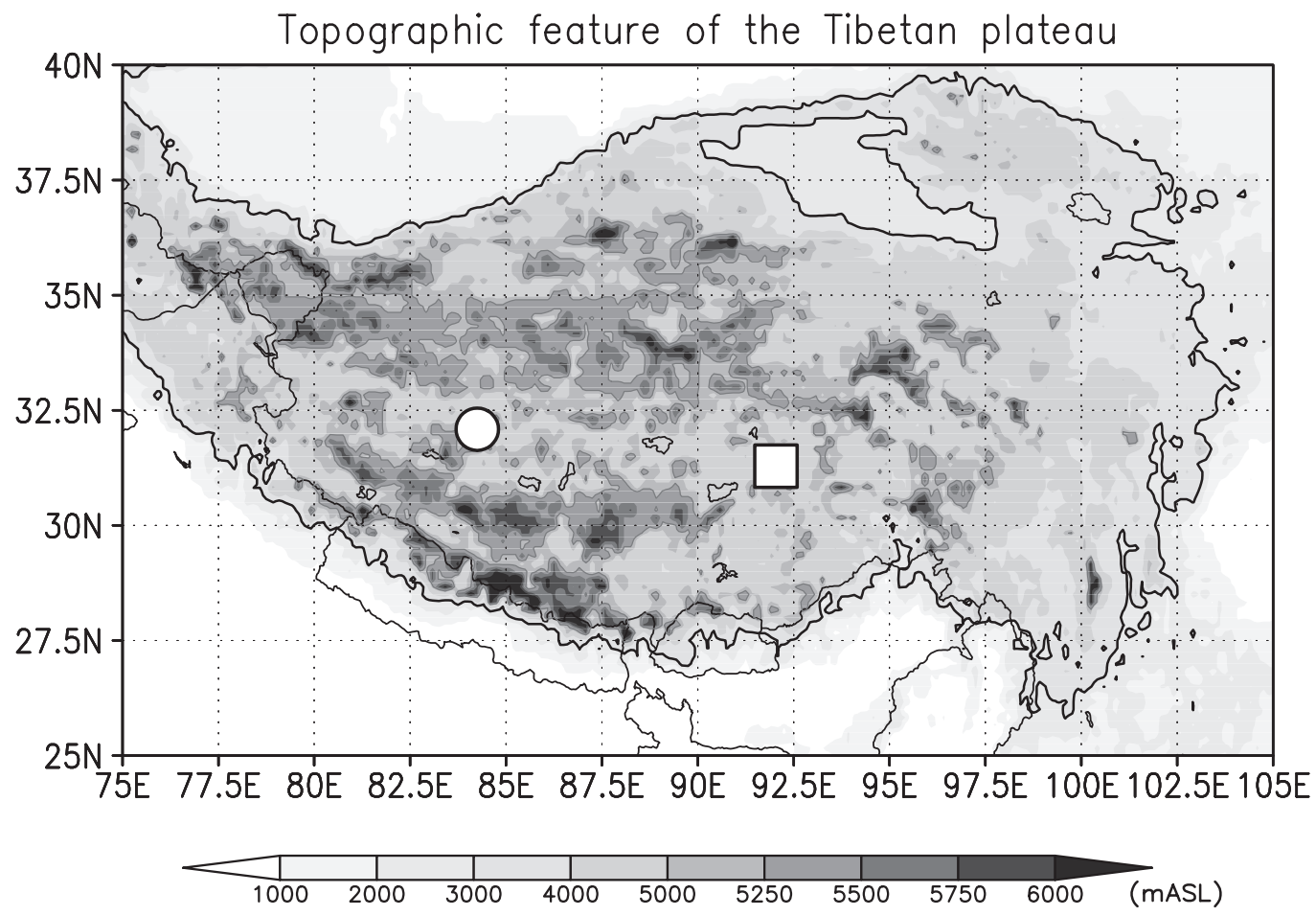

Fig. 1. Terrain of the Tibetan Plateau. The open circle and square indicate Gaize and Naqu respectively.

System (JCDAS) is used. The JCDAS product was produced under the same conditions as for the Japanese 25 year reanalysis product (JRA-25). JRA-25 is a joint research project between the JMA and Central Research Institute of Electric Power Industry. The resolution of the global model used in JRA-25 is T106L40 and the height of the top layer is $0.4 \mathrm{hPa}$. The assimilation method employed is the three-dimensional variational analysis (3DVar). An advantage of JRA-25 is that the precipitable water product obtained by the Special Sensor Microwave/Imager (SSM/I) onboard the Defense Meteorological Satellite Program (DMSP) series of polar orbiting satellites and the radiance data recorded by the TIROS Operational Vertical Sounder (TOVS) are assimilated. Details are available in Onogi et al. (2007).

The importance of cumulus convection to atmospheric heating over the plateau before the rainy season is shown by Taniguchi and Koike (2007). In the present paper, seasonal variation in the cumulus activity is examined and the relationship with the atmospheric temperature discussed. For that purpose, we used the brightness temperature $\left(T_{B}\right)$ data recorded by the Multi-functional Transport Satellite (MTSAT) launched by the Japan
Aerospace Exploration Agency (JAXA). To investigate cumulus activity, IR1 channel data (a wavelength of $10.3-11.3 \mu \mathrm{m}$ ) are used. In the range of IR1, the observed $T_{B}$ correctly corresponds to the physical temperature of objects and is useful in detecting the cloud top and investigating cumulus activity.

Cumulus convective activity around the Tibetan Plateau is also investigated using outgoing longwave radiation (OLR) data from the National Oceanic and Atmospheric Agency (NOAA). Although the original observation has gaps, the data set is filled by temporal and spatial interpolation (Liebmann and Smith 1996). Daily interpolated OLR data are obtained from twice-daily observations with advanced very-high-resolution radiometer (AVHRR) instruments onboard TIROS $\mathrm{N}$ and the NOAA series of satellites. NOAA interpolated OLR data are available from June 1974 to the present with spatial resolution of $2.5^{\circ} \times 2.5^{\circ}$.

\section{Observation results}

Figure 2 presents time-height cross sections of the difference in potential temperature $(P T)$ between two consecutive radiosonde observations for Gaize in IOP1 and IOP2. The results can be 

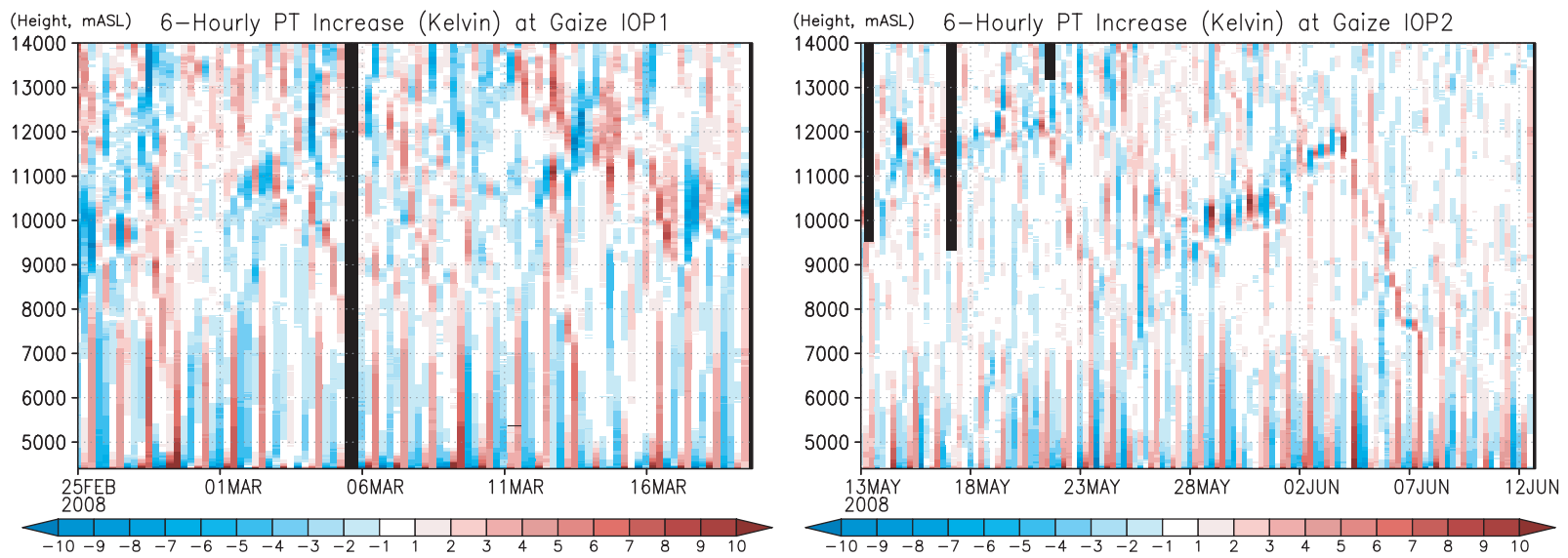

Fig. 2. Time series of the increase in $P T$ between each two observation for Gaize. The left panel is the result for IOP1 and the right for IOP2. The vertical and horizontal axes are the height and time respectively. Red colors indicate increase in $P T$, and blue decrease. Grids shaded black indicate missing values. The unit of values is Kelvin.

assumed to represent the increase in $P T$ during a 6-hour period. In IOP1, there is clear diurnal variation mainly below $8000 \mathrm{mASL}$, or both a significant increase in $P T$ during the day and decrease at night. The increase in $P T$ reached $9000 \mathrm{mASL}$ on some observation days. Although such diurnal variation is also observed in IOP2, the clear diurnal cycle is limited to layers lower than those in IOP1. In the upper layer (above $8000 \mathrm{mASL}$ in IOP1 and $9000 \mathrm{mASL}$ in IOP2), there is no clear diurnal cycle and a tendency of atmospheric warming/cooling continues for several days. Figure 3 is the same as Fig. 2 but for Naqu. As seen for Gaize, there is clear diurnal variation near the surface both in
IOP1 and IOP2, and again, there is no such feature in the upper layers. The results indicate that the atmospheric temperature changes through different processes in the lower and upper layers, both in IOP1 and IOP2. In past studies, the western and eastern plateau are distinguished by quite different climate conditions as dry and wet regions; however, the results in Figs. 2, 3 show similar features of the seasonal variation in $P T$ both in the west and east during early spring and the pre-monsoon season.

Figure 4 shows a time series of $P T$ at several heights observed by radiosonde during IOP1 for Gaize and Naqu. A linear regression line is drawn for each time series. The observation data are
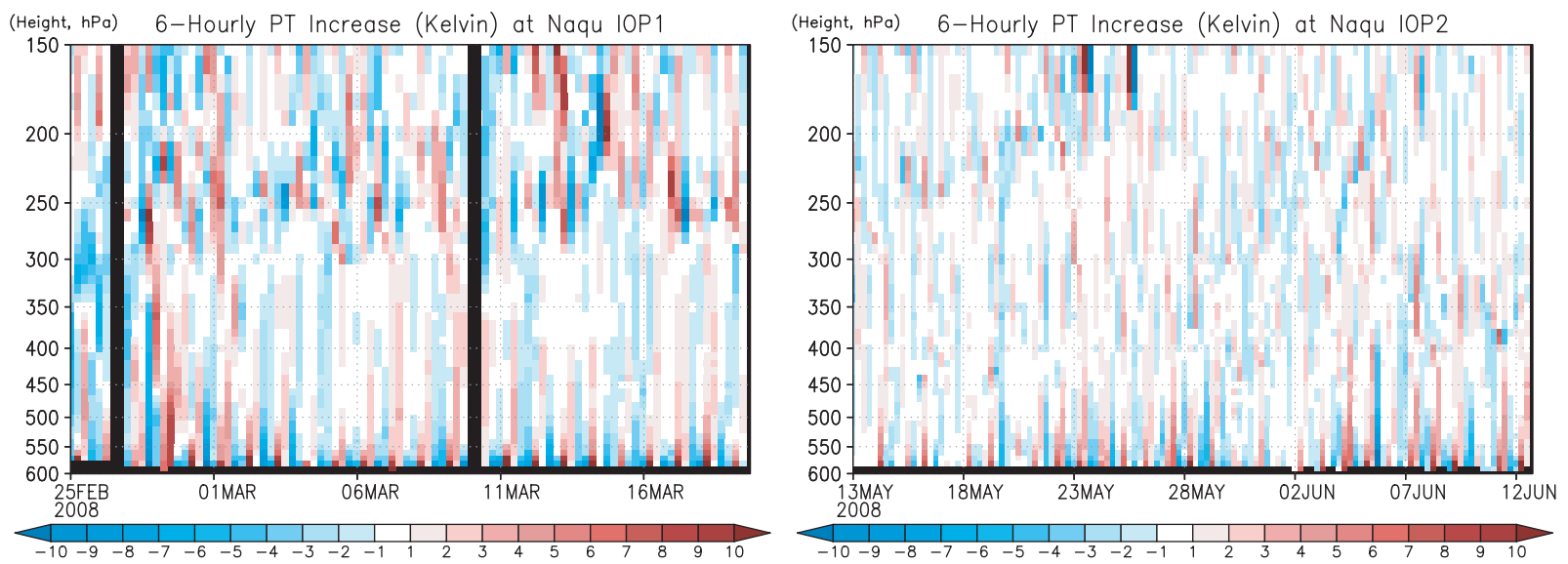

Fig. 3. Same as Fig. 2 but for Naqu. 

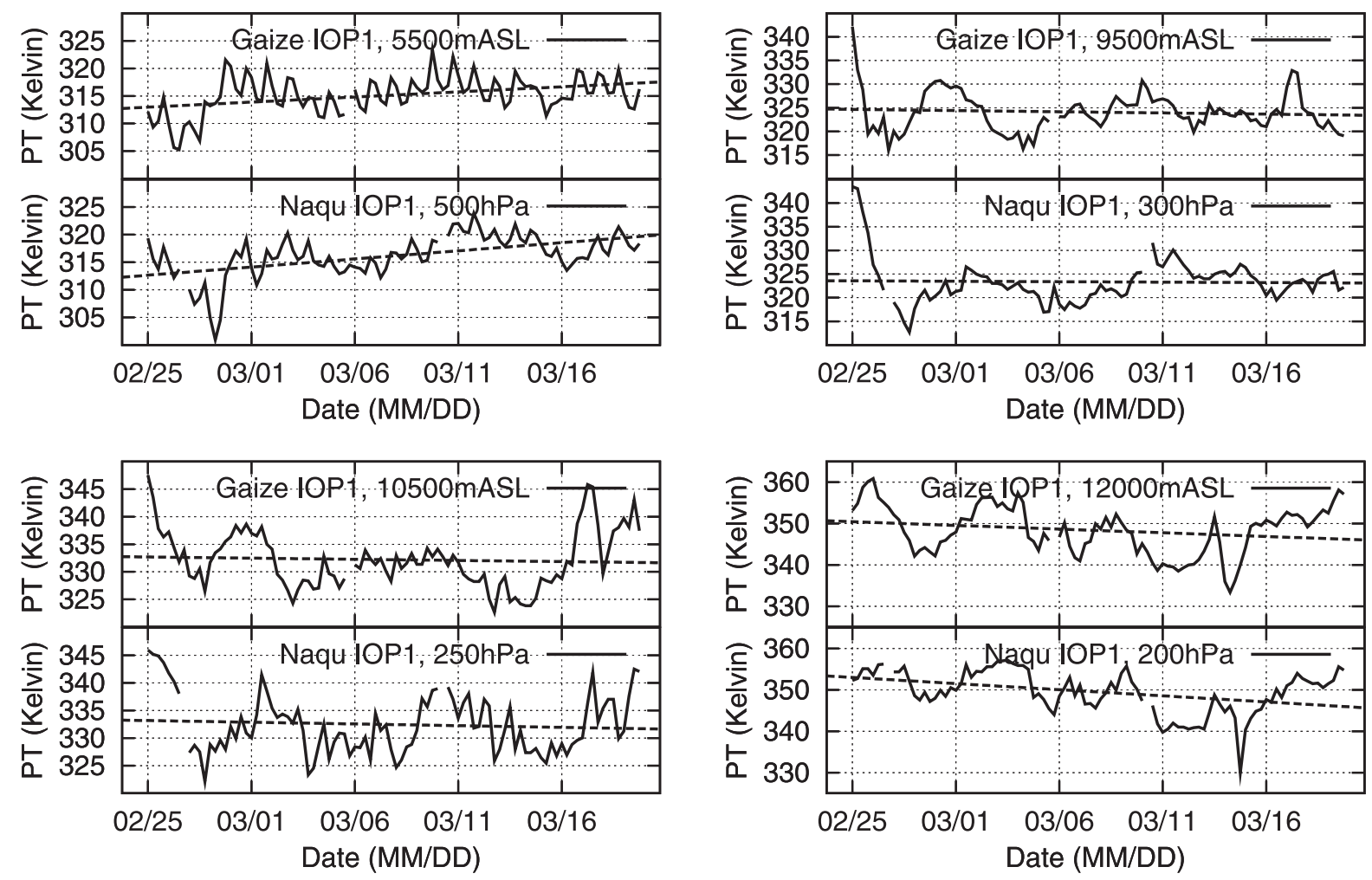

Fig. 4. Time series of $P T$ in IOP1 for each layer above Gaize and Naqu. Broken lines indicate linear regression. The $\mathrm{x}-$ and $\mathrm{y}$-axis are for date and $P T$, respectively.

recorded with different height formats for Gaize and Naqu, and the results are compared for two close layers. The compared layers are not exactly the same for the two locations but are considered to have similar tendencies.

At $5500 \mathrm{mASL}$ for Gaize and $500 \mathrm{hPa}$ for Naqu, near the surface, the linear regression line of $P T$ indicates a slightly increasing trend during IOP1. A Mann-Kendall trend test for these time series confirms the increasing trend at a 1\% significance level. There is no clear trend for $P T$ at $9500 \mathrm{mASL}$ for Gaize and $300 \mathrm{hPa}$ for Naqu. The Mann-Kendall trend test shows an increasing trend for those levels at both sites but the results are not significant. $P T$ at $10,500 \mathrm{mASL}$ and $P T$ at $200 \mathrm{hPa}$ do not have significant trends either. Figure 4 shows a decreasing trend of $P T$ at $200 \mathrm{hPa}$ for Naqu, which is confirmed by the Mann-Kendall test. On the other hand, no clear trend is statistically suggested at 12,000 mASL for Gaize. The results for the four layers indicate that there is an increasing trend in $P T$ near the surface but no significant trend in the middle or upper troposphere over the Tibetan Pla- teau during IOP1 or early spring. Comparing data for Gaize and Naqu, there is some similarity in the temporal variation in $P T$. For example, in the period 25 February-1 March, PT decreased significantly at 9500 and 10,500 mASL for Gaize and 300 and $250 \mathrm{hPa}$ for Naqu. Such co-occurring variation is also recognized in the lower layer (e.g., $5500 \mathrm{mASL}$ and $500 \mathrm{hPa}$ ) and the upper layer (e.g., 12,000 $\mathrm{mASL}$ and $200 \mathrm{hPa}$ ). The distance between Gaize and Naqu is about $900 \mathrm{~km}$, and thus the results indicate that the atmospheric temperature for Gaize and Naqu are affected by a synopticscale condition and the effect sometimes approaches the surface.

Figure 5 is the same as Fig. 4 but for IOP2. The linear regression lines of $P T$ indicate an increasing trend at 5500, 9500, 10,500 mASL for Gaize and $500,300,250 \mathrm{hPa}$ for Naqu. Results of the MannKendall trend test for those time series confirm the increasing trend during this period. At the same time, $P T$ at $12,000 \mathrm{mASL}$ for Gaize has an increasing trend. The linear regression line of $P T$ at $200 \mathrm{hPa}$ for Naqu shows only a slight increase, but 

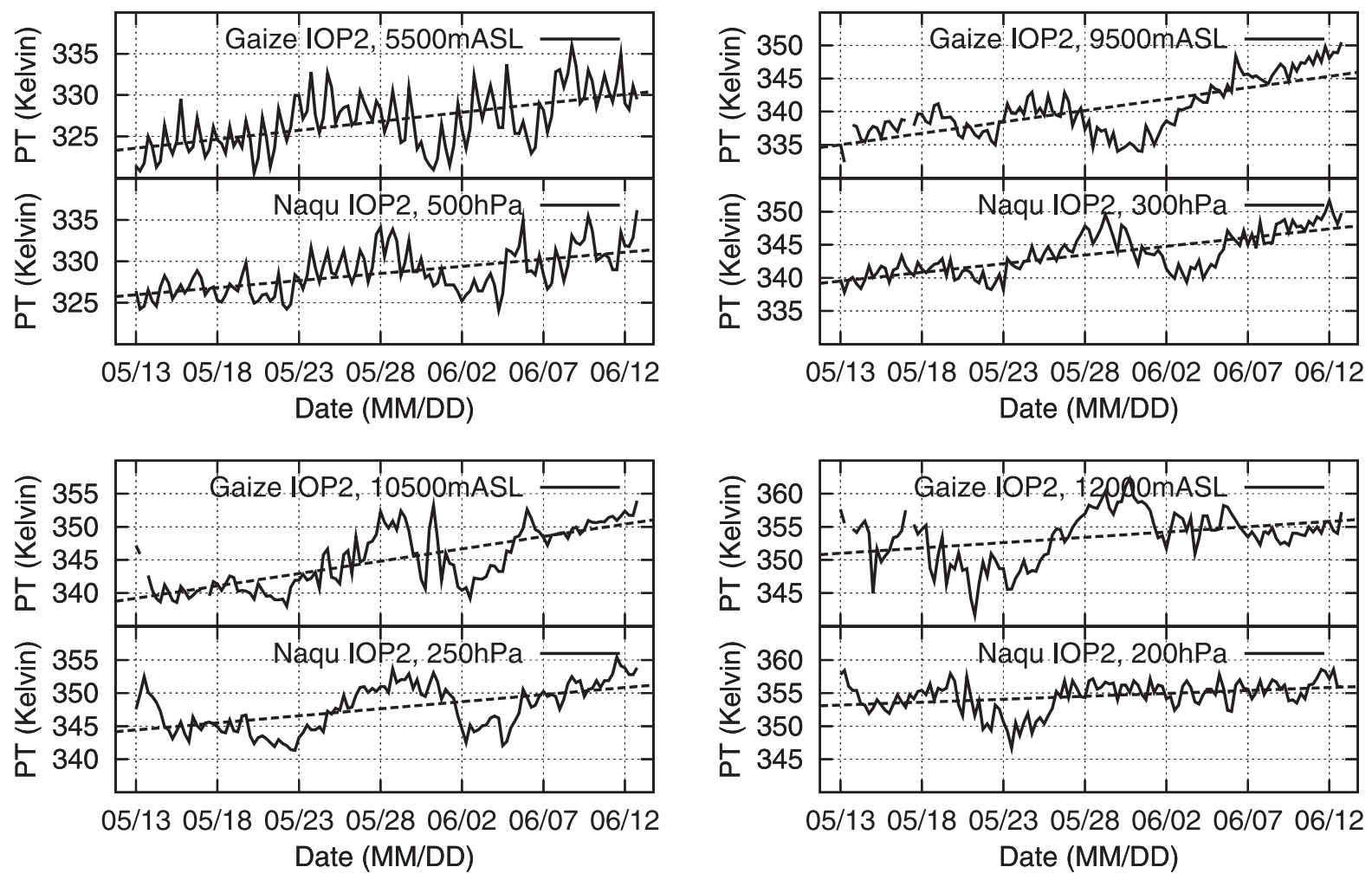

Fig. 5. Same as Fig. 4 but for IOP2.

the Mann-Kendall trend test confirms the trend. Therefore, the atmosphere is warming up in each layer from the surface to the upper troposphere over the plateau in IOP2. In IOP1, PT for Gaize and Naqu has similar temporal variations in some periods (Fig. 4), and such similarity in temporal variation at both sites is also recognized in IOP2 and the effect of synoptic-scale conditions is seen even in the pre-monsoon season.

Figure 6 shows the vertical profiles of the total increase in $P T$ (or difference in $P T$ between the first and last days in each IOP), the slope of linear regression line for $P T$ at each level, the mean daytime increase in $P T$ (or difference in $P T$ between 07 and 19 BST averaged for each IOP) and the mean profile of $P T$ for Gaize and Naqu. Figure 6a shows that the total increase in $P T$ is quite different between IOP1 and IOP2 for Gaize. The slope of the linear regression line, or linear trend, is derived from 6-hourly observations and the unit is Kelvin per 6-hour interval. A significant (insignificant) trend is indicated by white (black). In IOP1, the total increase in $P T$ is only $2-3 \mathrm{~K}$ and limited to below $8000 \mathrm{mASL}$ or so. From 8000 to
$10,500 \mathrm{mASL}$, there is a layer with notable cooling; however, the Mann-Kendall trend test does not confirm a clear trend. Therefore, this cooling is simply the difference in $P T$ between the last and first days of IOP1. In IOP2, a significant increase in $P T$ is recognized from the surface to the upper troposphere (Fig. 6a). The magnitude of the increase is much larger than that in IOP1 and the maximum increase in $P T$ is observed at around $9500 \mathrm{mASL}$. The vertical profile of the trend for IOP2 is similar to that of the total heating. However, the largest increasing trend is observed around 10,500 mASL, at a level higher than the level of the greatest total increase in $P T$. As mentioned above, the total increase in $P T$ is simply the difference between two observations and does not correctly represent the feature of heating. Although the total increase in $P T$ shown in Fig. 6a is small, substantive heating is expected in upper layers.

The mean daytime increase in $P T$ for Gaize in IOP1 shows that the atmosphere is warmed below around $9000 \mathrm{mASL}$ (Fig. 6b). The increase in PT is largest at the surface because of the high intensity of incoming shortwave radiation over the plateau 


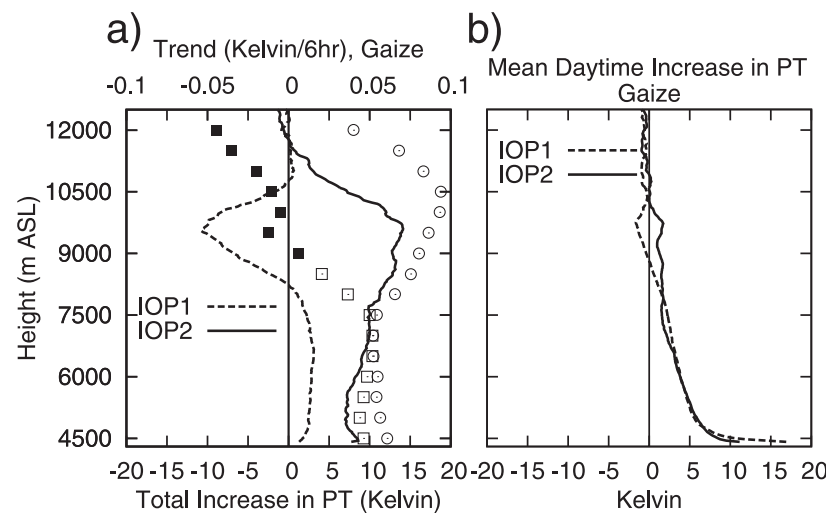

c)

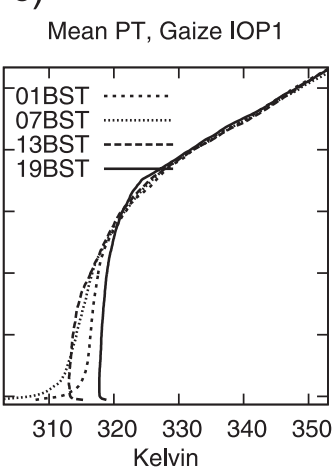

g)
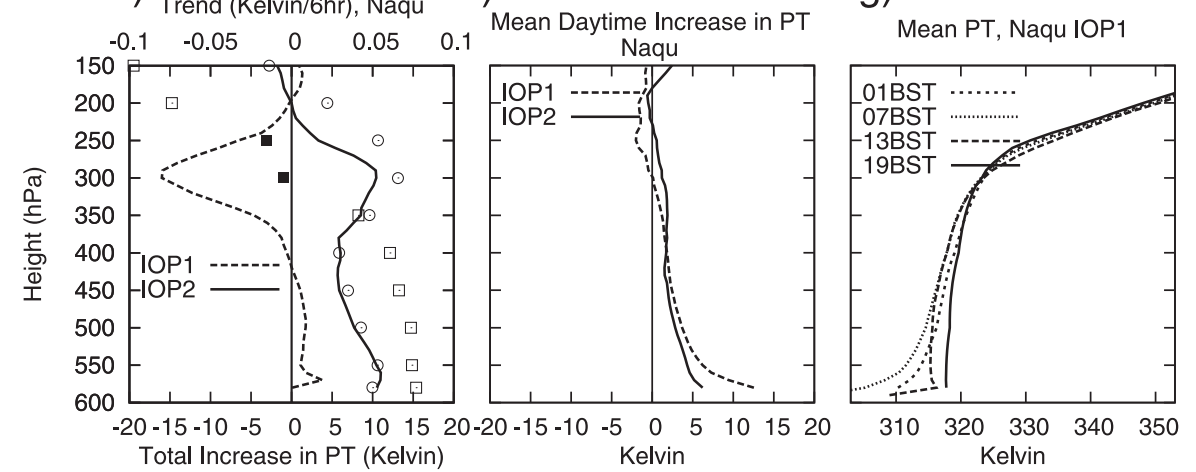

d)

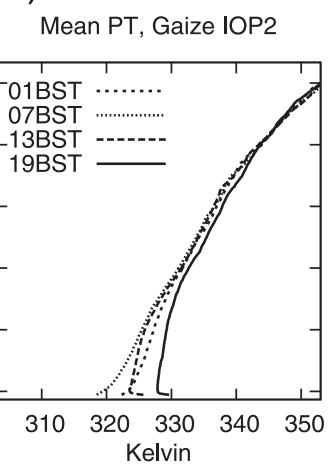

h)

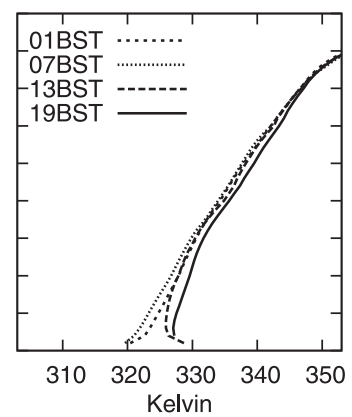

Significant Trend IOP1

: Insignificant Trend IOP1

O: Significant Trend IOP2

Fig. 6. Vertical profiles of: a) and e) total increase in $P T$ during each IOP and the slope of the linear regression line (trend), b) and f) mean daytime increase in $P T, \mathrm{c}), \mathrm{d}), \mathrm{g}$ ) and h) mean $P T$ for each observation time. Results are shown for IOP1 and IOP2. Upper panels are for Gaize and lower panels for Naqu. For the trends, significance at the 5\% level according to a Mann-Kendall trend test are indicated by an open square and circle for IOP1 and IOP2, respectively. Insignificant results are shown by black squares (no insignificant results for IOP2). For a) and e), the x-axis at top is for the trend and that at bottom for total increase in $P T$.

and the increase in $P T$ then reduces with height. Figure 6a shows the total heating during IOP1 is limited to below $8000 \mathrm{mASL}$; however Fig. 6b shows an increase in $P T$ during the day to a height of around $9000 \mathrm{mASL}$. This discrepancy is thought to be due to significant cooling at night, which is recognized in Fig. 2. The mean profiles of $P T$ in IOP1 show that there is an absolutely unstable layer near the surface at 1300 BST, and a strong upward flow is expected to be formed. At 1900 BST, $P T$ is vertically constant and significant increase in $P T$ from 1300 BST is recognized below around $8500 \mathrm{mASL}$. These results indicate the development of a deep mixing layer during the day, or between 1300 and 1900 BST (Fig. 6c). In this mixing layer, the atmosphere is effectively warmed, which results in the large $P T$ increase shown in Fig. 6b. In IOP2, the top of the mean daytime increase in $P T$ is slightly below 10,500 mASL (Fig. 6b) and lower than the highest point of the total heating in IOP2 (Fig. 6a). These results indicate an increase in $P T$ even at night in the upper layer. The mean profile of $P T$ in IOP2 is quite different from that in IOP1 (Fig. 6d). The profile indicates that the atmosphere has rather stable stratification, and thus, there is little dry convection. Under such a condition, effective heating due to the development of a mixing layer cannot be expected. However, as 
described above, Fig. 6b shows clear daytime increase in PT above $9000 \mathrm{mASL}$ in daytime and the significant total increase is recognized in the much higher levels than that.

Similar characteristics are observed for Naqu. In IOP1, the mean PT profile indicates the development of a mixing layer which can explain the mean daytime increase in $P T$ reaching around $300 \mathrm{hPa}$ (Fig. 6g). On the other hand, the discrepancy between the tops of total and mean daytime increase in $P T$ can be explained by cooling at night as for Gaize. In IOP2, the total increase in $P T$ is largest near the surface, but a significant increase is observed in the upper troposphere (Fig. 6e). The profile of the trend shows the largest value at $300 \mathrm{hPa}$. Above $300 \mathrm{hPa}$, the increasing trend is easily recognized although total increase in $P T$ is not so great. As described in the case of Gaize, the total increase in $P T$ is simply the difference between two observations and sometimes the trend is missed. Tamura et al. (2010) investigated atmospheric heating using the results for $200 \mathrm{hPa}$. Therefore, from the climatological view, there is significant heating and a clear increasing trend in $P T$ in the upper layers above $300 \mathrm{hPa}$. Comparing the trends in IOP1 and IOP2, the former is greater below $300 \mathrm{hPa}$. However, the trend is derived from linear regression and could be greatly affected by temporal cooling around the end of February (Fig. 4). Therefore, here we should not say which the greater heating is. The mean $P T$ profiles in IOP2 suggest an intense mixing layer cannot develop (Fig. 6h). Therefore, as for Gaize, the heating in the upper troposphere cannot be explained by the development of a mixing layer.

Luo and Yanai (1984) evaluated the capability of dry convection. In their study, the observed maxi- mum surface $P T$ indicated a strong upward flow near the surface and the $P T$ profiles showed a clear increase in $P T$ between 00 and 12 UTC below $400 \mathrm{hPa}$. The $P T$ also showed a vertically constant profile, which is thought to be formed by mixing of upper and lower atmosphere, but such a profile was observed only below $400 \mathrm{hPa}$. These results in Luo and Yanai (1984) indicate a deep dry convection hardly developed. Thus, the heating in the upper layer cannot be caused by dry convection. Yanai and Li (1992) also noted large temperature difference between ground surface temperature and air temperature at $1.5 \mathrm{~m}$ forms dry thermal convection. However the atmospheric profiles shown in their study indicated stable stratification above $400 \mathrm{hPa}$ and deep dry convection cannot be expected. In addition, the atmospheric profiles shown in this study clearly show stable stratification in IOP2 (Fig. 6), and it evidence that the increase in $P T$ during this period cannot be explained by the process shown in the past studies.

Taniguchi and Koike (2007) summarized the importance of convective cloud activity to the increase in $P T$ over the Tibetan Plateau. They showed a significant increase in $P T$ in the upper troposphere in April, before the onset of rains on the plateau, with strong cumulus activity, using radiosonde observation and satellite data. And also, the seasonal variation in cumulus activity was investigated by Taniguchi and Koike (2008). They defined the index of cumulus activity occurrence (Ico) as

$$
\text { Ico }=250-\min \left(T_{B}(06 \mathrm{UTC}), T_{B}(12 \mathrm{UTC})\right)
$$

Figure 7 is the time-series of Ico for Gaize and Naqu derived from MTSAT IR1 from February to July, 2008. The values are averaged over $90.5^{\circ} \mathrm{E}-$
Ico Gaize 01Feb-31JUL 2008

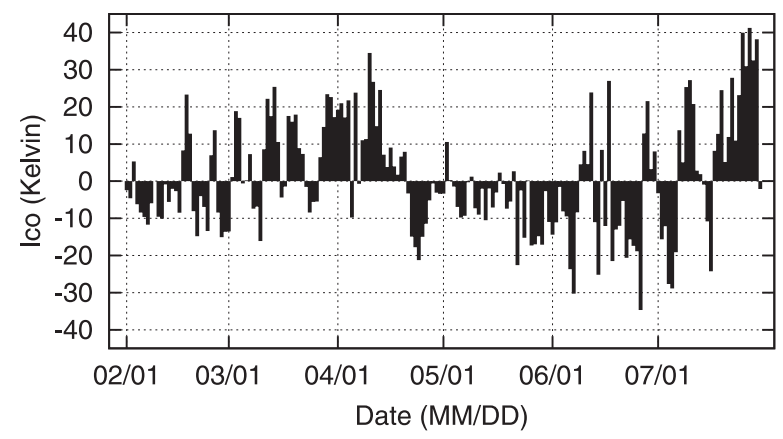

Ico Naqu 01Feb-31JUL 2008

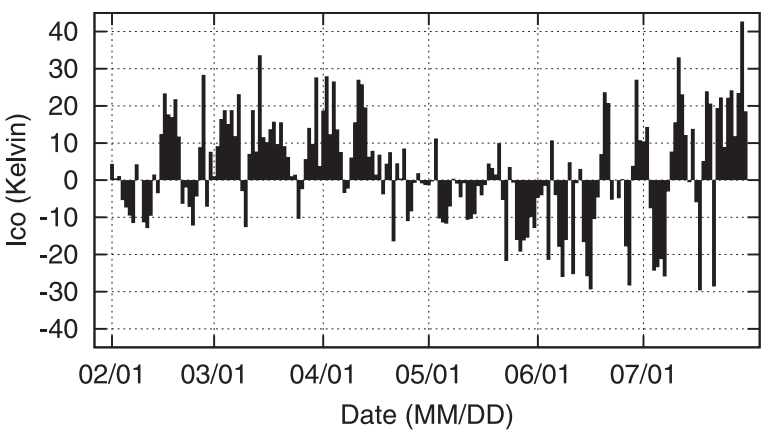

Fig. 7. Time series of Ico for Gaize and Naqu from early spring to summer. 
$93.5^{\circ} \mathrm{E}, 30.0^{\circ} \mathrm{N}-33.0^{\circ} \mathrm{N}$ for Gaize and $83.0^{\circ} \mathrm{E}-$ $86.0^{\circ} \mathrm{E}, 30.5^{\circ} \mathrm{N}-33.5^{\circ} \mathrm{N}$ for Naqu. From the beginning of February to early March, the frequency of cumulus activity is not high for Gaize and cumulus activity is often observed from mid-March to midApril. In Naqu, frequent cumulus activity is recognized from mid-February to mid-April. As seen in Fig. 4, there is no clear trend in $P T$ during IOP1, and thus, the effect of such cumulus activity on $P T$ is thought to be small. From mid-April to the end of June, including IOP2, cumulus activity is hardly observed at either observation site. The results indicate that the notable increase in $P T$ in the upper troposphere in IOP2 cannot be explained by latent heat release in the upper troposphere along with cumulus activity.

The $P T$ profiles by radiosonde observation and the seasonal variation of Ico show that the significant increase in PT during IOP2 is not due to dry or cumulus convection induced by local atmospheric conditions. In addition, difference in the heating process between the eastern and western part of the plateau has been pointed out in past studies. But there are some similarities in the atmospheric profiles, cumulus activities, and the temporal variation in $P T$ during IOP2. These results indicate that large scale process has a dominant function in the variation of $P T$ both in the east and west.

Thus, to understand the increase in $P T$ during IOP2, not only the local atmospheric conditions around Gaize and Naqu but also synoptic-scale conditions in the surrounding regions are important. The recent results of Tamura et al. (2010) reveal that upper tropospheric heating over the plateau is remotely induced by convective activity in the tropics in the form of adiabatic heating due to the downward motion of the Hadley-type circulation, and strongly suggests the importance of monsoon activity in a wide area of Asia as the heating system. In the next section, based on the past studies, synoptic-scale conditions around the plateau in 2008 are discussed.

\section{Discussion}

\subsection{Review of the past studies on the climatology}

Atmospheric heating around the Tibetan Plateau has been investigated from the standpoint of synoptic scale conditions in Asia. As introduced in Section 1, Murakami and Ding (1982), He et al. (1987) and Yanai et al. (1992) presented that large scale subsidence around the plateau associated with the general circulation is the dominant mechanism for the temperature increase.

Recently, Tamura et al. (2010) elucidated a detail process of the warming in upper troposphere over the Tibetan Plateau in pre-monsoon season. They showed that pre-monsoon heating over the plateau is due to adiabatic heating with downward motion over the western plateau, which is a compensation for the Hadley-type circulation induced by convective activity in the tropics. They verified this process by numerical simulations. Removing the latent heat flux around the Bay of Bengal (BoB), the heating around the plateau was greatly reduced. On the other hand, the changes in the heating was small when the sensible and latent heat flux from the plateau was eliminated. Yanai et al. (1992) suggested the subsidence motion in the west of the plateau is due to the upward motion over the plateau. But the process shown in Tamura et al. (2010) is thought to be a convincing explanation. Discussion in Yanai et al. (1992) is based on the results in 1979. However, Tamura et al. (2010) investigated a climatological condition based on a long-term reanalysis data, and it seems a general process of the heating over the plateau.

\subsection{Synoptic-scale conditions in 2008}

Based on the process illustrated in Tamura et al. (2010), synoptic scale conditions during IOP2 in 2008 are investigated. Figure 8 shows $P T$, the geopotential height, and the wind vector at $300 \mathrm{hPa}$ from 25 May to 8 June. On 25 May, there is a warm core over the BoB, and it spreads around 27-29 May. A southwesterly is recognized in the southern periphery of the plateau, and it can transfer the warm air onto the plateau. From 29 May, a warmer air mass spreading over the southern Tibetan Plateau. On 2 June, the warmer air reaches Pakistan and Afghanistan. From 4 to 6 June, a warmer region ( $P T$ higher than $346 \mathrm{~K}$ ) spreads westward to the Arabian Peninsula. On 8 June, the warmer region spreads from the base of the Arabian Peninsula to the Indochina Peninsula, centering on northeastern India. There is a strong westerly along $25^{\circ} \mathrm{N}$, where the warmer air spreads, and the result indicates the spreading warmer air is not due to horizontal advection.

Figure 9 shows the variation in $P T$ and mean vertical velocity over 10 days in the early and late parts of IOP2. The results are derived using JRA-25. In early IOP2 (13 May-22 May), substantial downward motion is observed from India to 

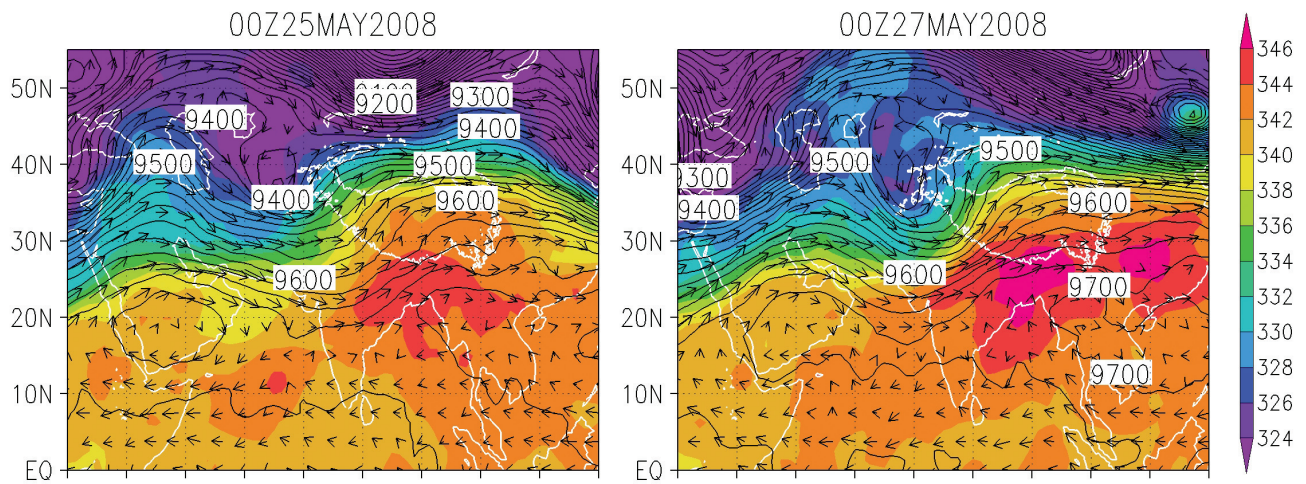

O0Z29MAY2008
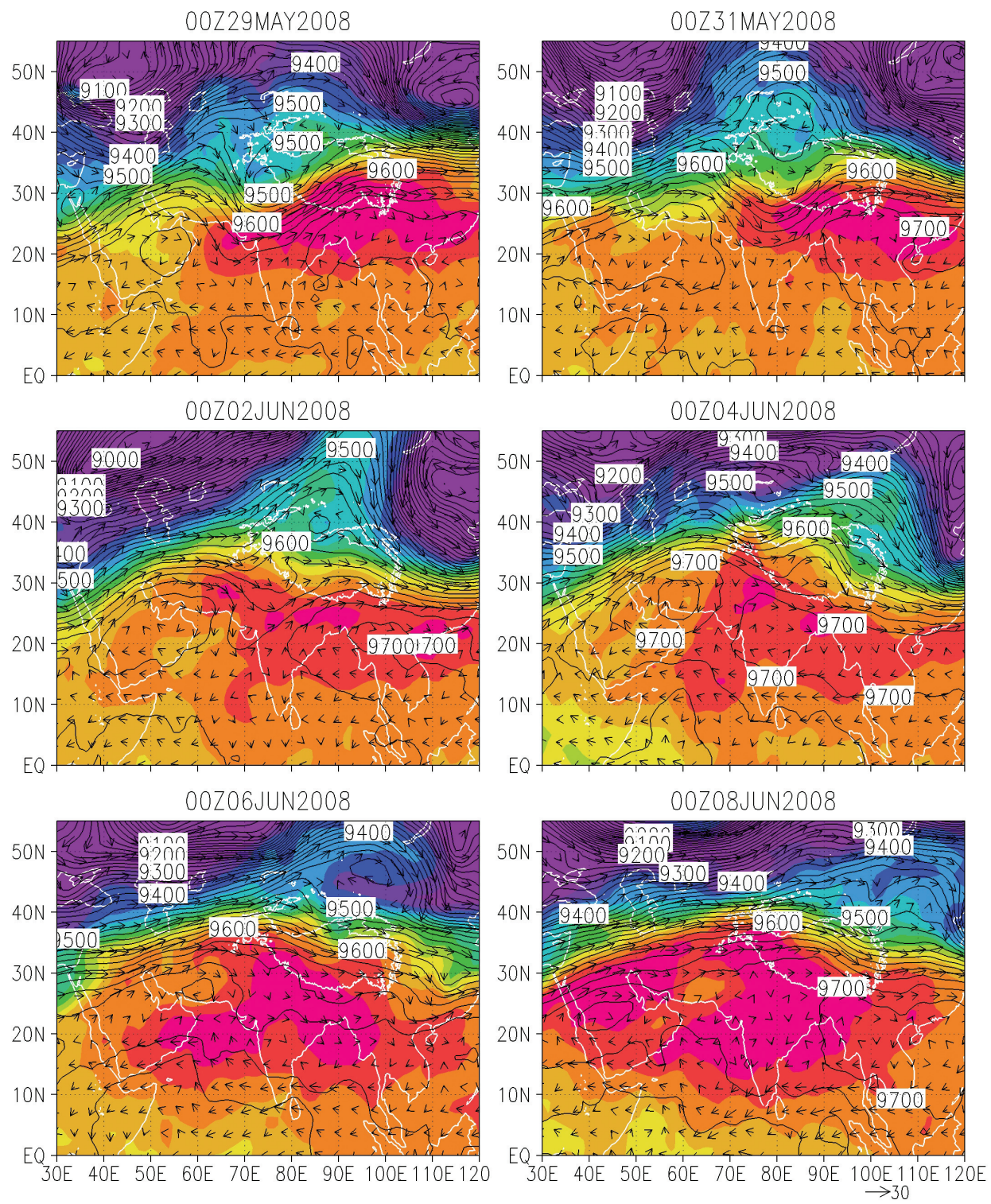

Fig. 8. $P T$, wind and geopotential height at $300 \mathrm{hPa}$ from 25 May to 8 June. The colors and contour lines indicate $P T$ (Kelvin) and geopotential height $(\mathrm{m})$, respectively. The vectors indicate wind direction and wind speed. The results are shown for every two days. 

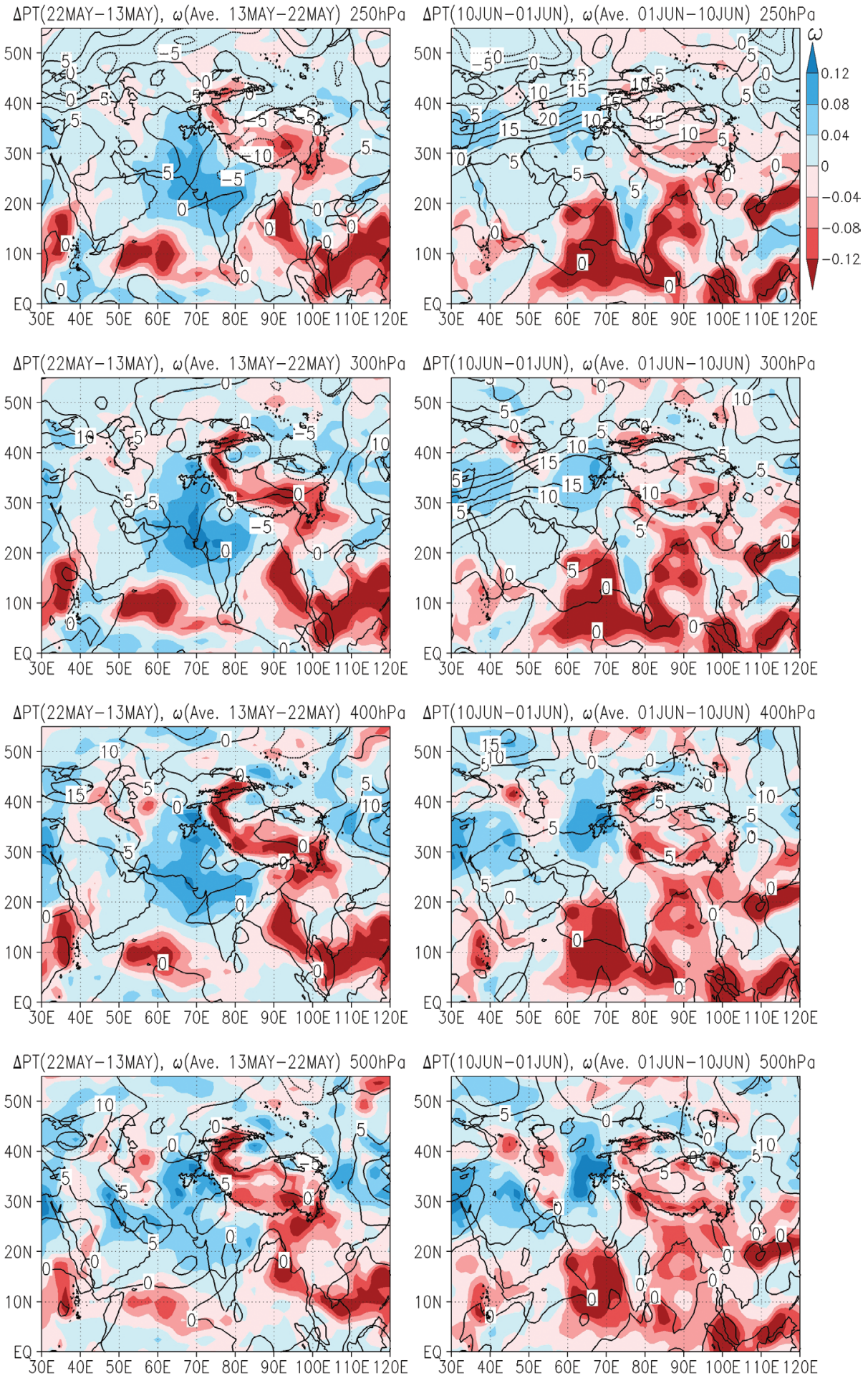

Fig. 9. Mean vertical p-velocity for 10 days in the early IOP2 (13-22 May) and the late IOP2 (1-10 June). Variations in $P T$ during the same 10-day periods are also plotted. Results are for 250, 300, 400 and $500 \mathrm{hPa}$ from the top. Colors indicate the mean p-velocity and contours indicate the variation in $P T$. The unit for the p-velocity and the variation of $P T$ are $\mathrm{Pa} / \mathrm{s}$ and Kelvin, respectively. 
Pakistan in each layer. As denoted in $\mathrm{He}$ et al. (1987), this is the downward motion accompanied by anticyclonic circulation over the Arabian Peninsula shown in Fig. 8. On the other hand, significant upward motion is recognized in the BoB, the South China Sea, and the southern Arabian Sea. The upward motion indicates cumulus activities in this region, and the warm core over the BoB seen on 25 May is thought to be formed by latent heat release accompanied by the cumulus convection in that region. There is also clear upward flow over the Tibetan Plateau in early IOP2. However, Fig. 7 show less cumulus activity during this period and the upward flow does not indicate cumulus convection. The variation in $P T$ indicates that there is some decrease in $P T$ over the plateau at $250 \mathrm{hPa}$, and no clear variation at other layers in the early IOP2.

In late IOP2 (1 June-10 June), the area with significant upward flow becomes larger than in the early IOP2, especially in the Arabian Sea and the south of the BoB. The expansion of the significant upward flow indicates the enhancement of convective activity in South Asia, or the onset of the Indian summer monsoon. The upward flow over the Tibetan Plateau becomes weaker than in the early IOP2. On the other hand, the area with significant downward motion is recognized in the west of the plateau. Between the areas with upward and downward flow, as shown in Tamura et al. (2010), the Hadley-type circulation is thought to be formed. At 300 and $250 \mathrm{hPa}$, noticeable increase in $P T$ is recognized around the area of the significant downward flow. Tamura et al. (2010) showed the atmospheric heating in the west of the plateau is due to the downward motion of the Hadley-type circulation, and the results in Fig. 9 indicate the same process. The increasing $P T$ is large at $300 \mathrm{hPa}$ and $250 \mathrm{hPa}$, but also recognizable at $400 \mathrm{hPa}$ (Fig. 9). There is a significant increase in $P T$ and a clear heating trend in this layer (Figs. 6a, e), but the mixing layer hardly reaches this height (Figs. 6d, h). Therefore, adiabatic heating due to the downward flow induced by cumulus convection in the tropics can affect those layers. On the other hand, there is no clear increase in $P T$ at $500 \mathrm{hPa}$. Although a downward motion is observed, the effect is quite small for this layer. There is one notable feature in the $P T$ variation in the late IOP2. The region with clear downward motion is limited, but the increase in $P T$ is widely observed from the subsidence area to the east of the plateau (Fig. 9). Same features were observed in Tamura et al. (2010) and the heat budget analysis in their study showed the heating in the east of the subsidence caused by horizontal advection. Figure 8 shows strong westerly above the subsidence area and the Tibetan Plateau, and the increasing $P T$ in upper layer over the plateau is due to the transportation of warmed air by horizontal advection.

Correspondence of the temporal variations of $P T$ observed by in-situ observation and the synoptic scale conditions are investigated. Figure 10 is the time-series of OLR averaged over South Asia $\left(60^{\circ} \mathrm{E}-100^{\circ} \mathrm{E}, \quad 5^{\circ} \mathrm{N}-20^{\circ} \mathrm{N}\right)$ and $P T$ at $10,500 \mathrm{mASL}$ for Gaize at $300 \mathrm{hPa}$ for Naqu. The heating trend are largest in these layers (Figs. 6a, e), and clear temporal variation is observed during this period. Before 21 May, there are no clear variation in PT at Gaize and Naqu, and OLR. The decreasing OLR indicates convective activity from 21 May. At the same time, $P T$ increases both for Gaize and Naqu. In Section 3, it is shown that dry or cumulus convection cannot cause the significant increase in $P T$ in the upper layer during IOP2. From 21 to 29 May, Figs. 8, 9 indicate that the warm core around the $\mathrm{BoB}$ is formed by latent heat release related to the convective activity in that region. At the same time, there is no warm region in the west of the Tibetan Plateau (Fig. 8). Therefore, the increase in $P T$ for Gaize and Naqu from 24 to 28 May is thought to be mainly due to the latent heat release around the $\mathrm{BoB}$, and the effect of subsidence motion is thought to be small.

Figure 10 shows significant cooling from 30 May in upper troposphere for Gaize and Naqu. In Fig. 8 , a cooler air mass is located in the west of the Tibetan Plateau on 25 May and it moves eastward and passes over the plateau by 2 June. Therefore, the cooling shown in Fig. 10 is due to the synopticscale condition. Fujinami and Yasunari (2004) examined the sub-monthly variation in convective activity and atmospheric circulation around the plateau and showed that a meandering flow moves dry and cold air onto the plateau and suppresses convective activity over the plateau. Although they mainly focused on convective activity and the target period was summer, the consideration of synoptic-scale mid-latitude conditions is indispensable in understanding the plateau meteorology.

A clearly increasing $P T$ is observed from 3 June for Gaize and Naqu (Fig. 8) after the passing of the synoptic-scale cooler air-mass. From 2 June, although the time series of $P T$ has a monotonously increasing trend (Fig. 10), the warmer region 
PT at 10500 mASL Gaize, 300hPa Naqu, and OLR in South Asia

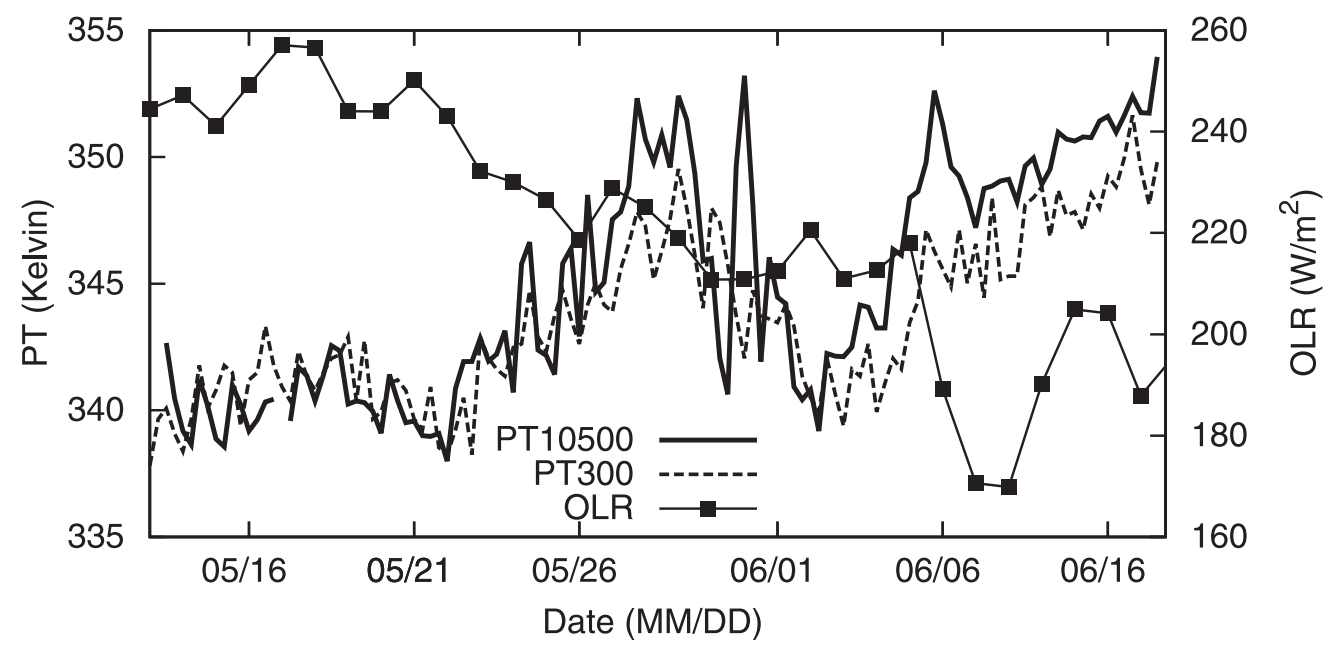

Fig. 10. Time series of OLR and PT. The line with square is OLR averaged for South Asia $(60 \mathrm{E}-100 \mathrm{E}$, $5 \mathrm{~N}-20 \mathrm{~N}$ ). Thick solid line is $P T$ at $10,500 \mathrm{mASL}$ observed in Gaize, and broken line is at $300 \mathrm{hPa}$ in Naqu. The y-axis at the left is for $P T$ and that at the right is for OLR. The unit for $P T$ and OLR are Kelvin and $\mathrm{W} \mathrm{m}^{-2}$, respectively.

suddenly spreads from 6 June as shown in Fig. 8. On the other hand, the decreasing OLR shows enhancement of the cumulus activity in South Asia (Fig. 10). The results suggest that the enhancement of convective activity affects a wider region, and the increasing $P T$ is thought to be a response to convective activity.

Synoptic-scale conditions in IOP2 show that, as soon as there is convective activity in the $\mathrm{BoB}$ in late May, $P T$ increased significantly over the plateau. However, this is not expected to be due to adiabatic heating induced by the Hadley-type circulation accompanied by convection in South Asia, but latent heat release of convection at the BoB. At the same time, a cooler air mass related to synoptic-scale meandering flow cools the plateau even in the period of strong convection. With the cool air mass passing and enhancing the convective activity, the warmer air suddenly spread while centered on the eastern plateau. This is adiabatic heating due to the downward motion of the Hadleytype circulation. Tamura et al. (2010) showed climatological process of the heating over the plateau and summarized as an adiabatic heating induced by the Hadley-type circulation is a dominant mechanism. However, in the seasonal progression of a certain year, the variation in atmospheric temperature over the plateau is caused by a combination of several synoptic-scale processes.

\section{Summary and conclusions}

In this study, an increase in atmospheric temperature over the Tibetan Plateau in early spring and the pre-monsoon season in 2008 are investigated using dense and continuous data obtained by intensive observation, reanalysis data, and satellite products. The results are summarized as follows:

1) In early spring (IOP1), the radiosonde observation results show that a deep mixing layer develops and warms the air efficiently during the day. However, cooling at night is also significant and the total increase in temperature in early spring is small and limited to near the surface. Because of no intensive radiosonde observation in early spring before the JICA project, detail structures and features of atmosphere over the plateau in early spring are first shown in this study, and these results are important to reveal the entire seasonal variation of meteorological conditions over the plateau.

2) In the pre-monsoon season (IOP2), the total increase in $P T$ in that period and the mean daytime increase in $P T$ are remarkable. In past studies, dry thermal convection has been thought to cause the atmospheric heating over the plateau during the pre-monsoon season. However, the observation results in this study show a shallow mixing layer, and 
suggest the dry thermal convection cannot cause the atmospheric heating over the plateau in premonsoon season. At the same time, cumulus activity occurs less frequently in pre-monsoon season, and the increase in $P T$ in upper layers cannot be occurred by latent heat release associated with cumulus convection. The shallow mixing layer and the infrequent cumulus activity indicate that local meteorological phenomena cannot cause the upper tropospheric heating over the plateau in premonsoon season.

3) During the IOPs in 2008, the radiosonde observations were concurrently implemented in the eastern and the western plateau. In previous studies, differences in atmospheric conditions between the east and the west have been pointed out. However, the characteristics of the $P T$ profiles and the meteorological phenomena expected from the profiles are similar between them both in IOP1 and IOP2. At the same time, the temporal variations of PT show a simultaneity between the two sites.

The second and third results suggest the existence of a large-scale process which controls the atmospheric heating in the entire part of the Tibetan Plateau. Based on the Tamura et al. (2010), synoptic scale conditions are examined and the increase in $P T$ during IOP2 is discussed following the process proposed in their study.

The characteristics of atmospheric profiles and its diurnal variations are illustrated for IOP1 and IOP2. However, the seasonal transition between the two seasons remains to be studied. For that purpose, coordinated observation has to be implemented for longer term. On the other hand, same kinds of data have been obtained in the mature season of summer monsoon in 2008 and these observation results should be investigated in future.

\section{Acknowledgments}

The observation activity and research work in this study were supported by the Japan International Cooperation Agency (JICA). The authors are grateful for the use of Japanese 25-year reanalysis data provided by the Japan Meteorological Agency and the Central Research Institute of Electric Power Industry; MTSAT data distributed by Weather Home, Kochi University; and interpolated OLR data provided by the NOAA/OAR/ESRL PSD. We thank all the scientists and coworkers who participated in the observation activity of the JICA project.

\section{References}

Boos, W. R., and Z. Kuang, 2010: Dominant control of the South Asian monsoon by orographic insulation versus plateau heating. Nature, 463, 218223.

Duan, A., and G. Wu, 2005: Role of the Tibetan Plateau thermal forcing in the summer climate patterns over subtropical Asia. Clim. Dyn., 24, 793-807.

Fujinami, H., and T. Yasunari, 2004: Submanthly Variability of Convection and Circulation over and around the Tibetan Plateau during the Boreal Summer. J. Meteor. Soc. Japan, 82, 1545-1564.

He, H., J. W. McGuinnis, Z. Song, and M. Yanai, 1987: Onset of the Asian Summer Monsoon in 1979 and the Effect of the Tibetan Plateau. Mon. Weather. Rev., 115, 1966-1995.

Hsu, H.-H., and Y. Liu, 2003: Relationship between the Tibetan Plateau and East Asian summer monsoon rainfall. Geophys. Res. Lett., 30, doi:10.1029/ 2003GL017909.

Liebmann, B., and C. A. Smith, 1996: Description of a complete (interpolated) outgoing longwave radiation dataset. Bull. Am. Meteorol. Soc., 77, 12751277.

Luo, H., and M. Yanai, 1984: The Large-Scale Circulation and Heat Sources over the Tibetan Plateau and Surrounding Areas during the Early Summer of 1979. Part II: Heat and Moisture Budgets. Mon. Weather. Rev., 112, 966-989.

Murakami, T., and Y. Ding, 1982: Wind and Temperature Changes over Eurasia during the Early Summer of 1979. J. Meteor. Soc. Japan, 60, 183196.

Onogi, K., J. Tsutsui, H. Koide, M. Sakamoto, S. Kobayashi, H. Hatsushika, T. Matsumoto, N. Yamazaki, H. Kamahori, K. Takahashi, S. Kadokura, K. Wada, K. Kato, R. Oyama, T. Ose, N. Mannoji, and R. Taira, 2007: The JRA-25 Reanalysis. J. Meteor. Soc. Japan, 85, 369-432.

Tamura, T., K. Taniguchi, and T. Koike, 2010: Mechanism of upper tropospheric warming around the Tibetan Plateau at the onset phase of the Asian summer monsoon. J. Geophys. Res. 115, D02106, doi:10.1029/2008JD011678.

Taniguchi, K., and T. Koike, 2007: Increasing Atmospheric Temperature in the Upper Troposphere and Cumulus Convection over the Eastern Part of the Tibetan Plateau in the Pre-Monsoon Season of 2004. J. Meteor. Soc. Japan, 85A, 271294.

Taniguchi, K., and T. Koike, 2008: Seasonal Variation of Cloud Activity and Atmospheric Profiles over the Eastern Part of the Tibetan Plateau. J. Geophys. Res., 113, D10104, doi:10.1029/2007JD009321.

Ueda, H., H. Kamahori, and N. Yamazaki, 2003: Seasonal Contrasting Feature of Heat and Moisture 
Budgets between the Eastern and Western Tibetan Plateau during the GAME IOP. J. Climate, 14, 2309-2324.

Yanai, M., C. Li, and Z. Song, 1992: Seasonal Heating of the Tibetan Plateau and Its Effects on the Evolution of the Asian Summer Monsoon. J. Meteor. Soc. Japan, 70, 189-221.
Yanai, M., and C. Li, 1994: Mechanism of Heating and the Boundary Layer over the Tibetan Plateau. Mon. Wea. Rev., 122, 305-323.

Zhao, P., and L. Chen, 2001: Interannual Variability of Atmospheric Heat Source/Sink over the QinghaiXizang (Tibetan) Plateau and its relation to circulation. Advances in Atmospheric Sci., 18, 106-116. 